\title{
Smoking State Determined by Cotinine and Arterial Stiffness
}

\author{
Jiang Xie, MD; Dayi Hu, MD; Xian Wang, MD*; Yali Luo, MM**; Jinwen Wang, MD*
}

\begin{abstract}
Background: Exposure to active and passive smoking is associated with arterial stiffness and cotinine is an objective biochemical indicator to classify smoking state. The aim of the study was to survey participant smoking condition with cotinine in North China and discuss its destructive effect on arterial stiffness.

Methods and Results: Nine hundred and six people were recruited in this study and were classified into nonsmokers, passive smokers and active smokers according to the cotinine level. Brachial-ankle pulse wave velocity (baPWV) was measured using an automatic device. Active smokers vs non-smokers showed a significantly higher baPWV $(\mathrm{P}=0.023)$ after adjusting for covariates. Participants who smoked longer than 10 years had a higher baPWV than non-smokers $(\mathrm{P}=0.029)$ although no significant difference existed between those who had a smoking history of less than 10 years and those who had never smoked. In less developed areas, the active and passive smoking rates were higher than that in Beijing $(\mathrm{P}<0.001)$ while active smokers vs non-smokers had a higher baPWV $(\mathrm{P}=0.017)$.

Conclusions: Active smokers, as confirmed by the cotinine level have worse arterial stiffness, and long-term smoking can cause marked arterial stiffness. Smoking exposure might bring about more serious effects on arterial function in patients from poor areas than in modernized cities. (Circ J 2009; 73: 1537-1542)
\end{abstract}

Key Words: Arterial stiffness; Brachial-ankle pulse wave velocity; Cotinine; Smoking state

$\mathbf{C}$ igarette smoking is a major preventable risk factor for death in China! Several studies have demonstrated that exposure to active and passive smoking is associated with arterial stiffness ${ }_{-}^{2-7}$ which is an important pathological state of vascular damage and is closely related to atherosclerotic cardiovascular disease? Measurement of pulse wave velocity (PWV) is one of the most representative non-invasive techniques for assessing arterial stiffness. Simple methods to measure brachial-ankle PWV (baPWV) by recording the distensibility of the brachial and tibial arteries in just $5 \mathrm{~min}$ had been available for several years,, 10 and former studies have proven its favorable correlation with central PWV, as examined by invasive methods, ${ }^{11}$ and with other traditional risk factors for cardiovascular disease ${ }^{2}$ In previous studies to evaluate the harmful effect of cigarette exposure on arterial stiffness, a confidential questionnaire about smoking state was always administered during a specific interview by investigators! ${ }^{13,14}$ However, the information about smoking based on the questionnaire does not always indicate objective conditions $!^{15-19}$ Our aim was to investigate the smoking condition of patients from in North China, using cotinine, a sensitive and specific marker of active and passive exposure to tobacco, ${ }^{18-21}$ and discuss its impact on arterial stiffness.

(Received December 15, 2008; revised manuscript received March 17, 2009; accepted March 22, 2009; released online June 26, 2009)

School of Public Health and Family Medicine, Capital University of Medical Sciences, *Cardiovascular Center of Beijing Army General Hospital and **Institute of Basic Medicine, Capital University of Medical Sciences, Beijing, China

Mailing address: Dayi Hu, MD, School of Public Health and Family Medicine, Capital University of Medical Sciences, Beijing 100009, China. E-mail: hudayi_heart@yahoo.cn

All rights are reserved to the Japanese Circulation Society. For permis-

sions, please e-mail: cj@j-circ.or.jp

\section{Methods}

\section{Study Population}

Between January and August 2008, 906 people, aged 20-70 years, were recruited for this study in Beijing and Julu, a small town $400 \mathrm{~km}$ south of Beijing. These subjects included inpatients and outpatients as well as volunteers who underwent health-screening examinations in the medical examination centers. For the entire population, the exclusion criteria included patients who had a history of: (1) percutaneous coronary intervention and/or coronary artery bypass graft treatment; (2) aortic valve heart disease; (3) aortic aneurysm; (4) serious myocardial dysfunction with an ejection fraction of $<30 \%$; and (5) peripheral arteriosclerosis obliterans with an ankle-brachial index (ABI) of $<0.9$.

Self-reported smokers were defined if the subjects confessed to smoking cigarettes daily for at least 6 months and were further categorized as current and former smokers. Former smokers were included in this study if they had given up smoking for longer than 10 years and were ascribed as non-smokers during analysis. Thirty-seven people were excluded from the study because they had less than 10 years of smoking cessation.

All subjects gave written informed consent, and the study protocol was approved by the Beijing Army General Hospital. Fasting venous blood samples were drawn, and total cholesterol (TC), high-density lipoprotein-cholesterol (HDL-C), low-density lipoprotein-cholesterol (LDL-C), triglycerides (TG), and serum glucose were measured by using standard methods.

\section{Measurement of Cotinine}

The assay was performed using a commercial 96 well (STC Cotinine Micro-plate EIA, Cat.no.CT086D; Calbiotech Inc, Spring Valley, CA, USA). All reagents were brought to room temperature $\left(18-26^{\circ} \mathrm{C}\right)$ before use. The procedure used was as follows: add $10 \mu$ l of standards and serum to 
Table 1. Characteristics of the Study Cohort According to Smoking Status

\begin{tabular}{|c|c|c|c|c|c|c|}
\hline & \multirow{2}{*}{$\begin{array}{l}\text { Non-smokers } \\
\quad(\mathrm{n}=617)\end{array}$} & \multirow{2}{*}{$\begin{array}{l}\text { Passive smokers } \\
\qquad(\mathrm{n}=83)\end{array}$} & \multirow{2}{*}{$\begin{array}{l}\text { Active smokers } \\
\quad(\mathrm{n}=206)\end{array}$} & \multicolumn{3}{|c|}{$P$ value } \\
\hline & & & & A & $\mathrm{B}$ & $\mathrm{C}$ \\
\hline Age (years) & $47.2 \pm 12.3$ & $42.7 \pm 13.4$ & $46.5 \pm 11.3$ & 0.002 & 0.016 & 0.524 \\
\hline BMI $\left(\mathrm{kg} / \mathrm{m}^{2}\right)$ & $24.4 \pm 3.4$ & $24.5 \pm 3.4$ & $25.5 \pm 3.3$ & 0.738 & 0.028 & $<0.001$ \\
\hline HR (beats/min) & $70.6 \pm 9.7$ & $70.9 \pm 9.5$ & $71.6 \pm 10.8$ & 0.821 & 0.565 & 0.209 \\
\hline $\mathrm{SBP}(\mathrm{mmHg})$ & $128 \pm 20$ & $124 \pm 15$ & $132 \pm 17$ & 0.037 & 0.001 & 0.026 \\
\hline DBP (mmHg) & $78 \pm 12$ & $78 \pm 11$ & $82 \pm 11$ & 0.671 & 0.002 & $<0.001$ \\
\hline $\mathrm{ABI}$ & $1.10 \pm 0.08$ & $1.10 \pm 0.07$ & $1.11 \pm 0.08$ & 0.847 & 0.650 & 0.312 \\
\hline CIMT (mm) & $0.71 \pm 0.20$ & $0.68 \pm 0.19$ & $0.75 \pm 0.21$ & 0.133 & 0.003 & 0.009 \\
\hline $\mathrm{TC}(\mathrm{mmol} / \mathrm{L})$ & $4.80 \pm 0.93$ & $4.58 \pm 0.76$ & $4.80 \pm 0.99$ & 0.038 & 0.060 & 0.986 \\
\hline LDL-C (mmol/L) & $2.75 \pm 0.72$ & $2.62 \pm 0.71$ & $2.77 \pm 0.80$ & 0.141 & 0.119 & 0.706 \\
\hline HDL-C (mmol/L) & $1.34 \pm 0.28$ & $1.32 \pm 0.26$ & $1.30 \pm 0.26$ & 0.420 & 0.628 & 0.051 \\
\hline $\mathrm{TG}(\mathrm{mmol} / \mathrm{L})$ & $1.59 \pm 1.03$ & $1.83 \pm 1.32$ & $1.98 \pm 1.37$ & 0.607 & 0.313 & $<0.001$ \\
\hline Glucose $(\mathrm{mmol} / \mathrm{L})$ & $5.27 \pm 1.22$ & $5.17 \pm 0.87$ & $5.32 \pm 1.35$ & 0.511 & 0.039 & 0.017 \\
\hline Hypertension (\%) & $233(37.8)$ & $23(27.7)$ & $102(49.5)$ & 0.089 & 0.001 & 0.004 \\
\hline ACEI/ARB (\%) & $35(15.0)$ & $3(13.0)$ & $15(14.7)$ & 0.796 & 0.838 & 0.940 \\
\hline $\mathrm{CCB}(\%)$ & $58(24.9)$ & $7(30.4)$ & $23(22.5)$ & 0.809 & 0.427 & 0.338 \\
\hline No treatment $(\%)$ & $83(35.6)$ & $11(47.8)$ & $46(45.1)$ & 0.267 & 0.821 & 0.113 \\
\hline Diabetes $(\%)$ & $64(10.4)$ & $6(7.2)$ & $23(11.2)$ & 0.441 & 0.390 & 0.794 \\
\hline Any treatment $(\%)$ & $24(37.5)$ & $3(50.0)$ & $9(39.1)$ & 0.670 & 0.669 & 0.891 \\
\hline
\end{tabular}

A, Passive smokers vs Non-smokers; B, Active smokers vs Passive smokers; C, Active smokers vs Non-smokers; BMI, body mass index; HR, heart rate; SBP, systolic blood pressure; DBP, diastolic blood pressure; ABI, ankle-brachial index; TC, total cholesterol; LDL-C, low-density lipoprotein-cholesterol; HDL-C, high-density lipoprotein-cholesterol; TG, triglyceride; ACEI/ARB, angiotensinconverting enzyme inhibitor/angiotensin receptor blocker; $\mathrm{CCB}$, calcium channel blocker.

each well, and then $100 \mu \mathrm{l}$ of the enzyme conjugate to each well. Tap the sides of the plate holder to ensure proper mixing. Incubate for $60 \mathrm{~min}$ at room temperature $\left(18-26^{\circ} \mathrm{C}\right)$ in the dark, after the addition of an enzyme conjugate to the last well. Then wash the wells 6 times with $300 \mu$ distilled water using a plate washer taking care not to cross-contaminate wells. Invert wells and vigorously slap dry on absorbent paper to ensure all residual moisture is removed. Add $100 \mu \mathrm{l}$ of substrate reagent to each well and tap the sides of the plate holder to ensure proper mixing. And then incubate for $30 \mathrm{~min}$ at room temperature in the dark. Add $100 \mu \mathrm{l}$ of stop solution to each well to change the blue color to yellow. The cotinine concentration in each well was then quantified by measuring the light absorbance at wavelengths of $450 \mathrm{~nm}$ and comparing them with a standard curve; this technique is sensitive to $1 \mathrm{ng} / \mathrm{ml}$.

The participants who were regarded as non-smokers with no marked passive cigarette exposure had to have a serum cotinine level lower than $1 \mathrm{ng} / \mathrm{ml}$. Marked passive smoking was diagnosed when the level of serum cotinine ranged between 1 and $15 \mathrm{ng} / \mathrm{ml}$. The subjects were classified as active smokers when their cotinine levels exceeded $15 \mathrm{ng} / \mathrm{ml} !^{15,20,22}$

\section{Measurement of baPVW}

The baPWV was measured using an automatic device (Model BP-203PRE, Colin, Inc, Komaki, Japan). baPWV, systolic blood pressure (SBP), diastolic blood pressure (DBP), electrocardiogram, and heart sounds were recorded simultaneously. After a $5 \mathrm{~min}$ rest in the supine position, pressure waveforms of the brachial and tibial arteries were recorded with cuffs wrapped on both brachia and ankles, the electrocardiogram was recorded using electrodes placed on both wrists, and a microphone for detecting heart sounds was placed on the left edge of the sternum. The pressure waveforms obtained by the cuff were derived from a plethysmographic sensor that determines volume pulse form and an oscillometric sensor that measures blood pressure. Volume waveforms at the brachial and ankles were stored for a sampling time of $10 \mathrm{~s}$ with automatic gain analysis and quality adjustment. The time interval between the brachial and ankle (Tba) was the time interval between the initial rise in the brachial and tibial pressure waveforms. The distance between sampling points of baPWV was calculated automatically based on body height. The length from the aortic valve to the ankle (La) was estimated using the following equation: $\mathrm{La}=0.8129 \times$ height +12.328 (all values for length and height are in $\mathrm{cm}$ ). The length from the aortic valve to the brachial $(\mathrm{Lb})$ was estimated using the following equation: $\mathrm{Lb}=0.2195 \times$ height -2.074 . The baPWV was estimated using the following equation: $\mathrm{baPWV}=(\mathrm{La}-\mathrm{Lb}) / \mathrm{Tba}$. Bilateral baPWV and brachial and ankle blood pressures were measured automatically and simultaneously by this device. We used the mean value of the bilateral baPWV and only the left brachial blood pressure in our analyses.

\section{Statistics Analysis}

Continuous variables were presented as mean \pm standard deviation, and categorical variables were presented as percentages. A P value less than 0.05 was considered significant. A one-way ANOVA was used to compare the clinical characteristics of studied subjects among various smoking groups. Chi-square tests were used to compare proportions across groups. A partial correlation coefficient was reported for the association between cotinine and baPWV, which controlled for age, heart rate (HR), DBP, serum glucose, body mass index (BMI), TG, and gender. They were also added in the analysis of covariance (ANCOVA) model as covariates when comparing the differences of baPWV among different groups. The statistical calculations were performed with the SPSS 13.0 program.

\section{Results}

\section{Clinical Characteristics}

According to the cotinine level, 617 subjects were classified as non-smokers, 83 were diagnosed as obviously passive smokers, and 206 were diagnosed as active smokers. The median levels of cotinine for passive smokers and active 
Table 2. Comparision of baPWV Among Different Smoking Status and Different Smoking Duration

\begin{tabular}{|c|c|c|c|c|c|c|}
\hline \multirow[b]{2}{*}{ Smoking status } & \multicolumn{3}{|c|}{ Unadjusted analysis } & \multicolumn{3}{|c|}{ Adjusted analysis ${ }^{\#}$} \\
\hline & $\begin{array}{l}\mathrm{baPWV} \\
(\mathrm{cm} / \mathrm{s})\end{array}$ & $\begin{array}{c}\text { Difference } \\
(95 \% \mathrm{CI})\end{array}$ & $P$ value & $\begin{array}{l}\mathrm{baPWV} \\
(\mathrm{cm} / \mathrm{s})\end{array}$ & $\begin{array}{l}\text { Difference } \\
(95 \% \mathrm{CI})\end{array}$ & $P$ value \\
\hline Non-smokers & 1,407 & & & 1,396 & & \\
\hline Passive smokers & 1,346 & $-61.3(-128.5 \sim 6.0)$ & 0.740 & 1,403 & $6.4(-61.0 \sim 73.8)$ & 1.000 \\
\hline Active smokers & 1,441 & $34.6(-11.7 \sim 80.9)$ & 0.143 & 1,450 & $53.8(5.5 \sim 102.1)$ & 0.023 \\
\hline \multicolumn{7}{|l|}{ Smoking duration } \\
\hline 0 year & 1,407 & & & 1,405 & & \\
\hline$\leq 10$ years* & 1,227 & $-130.4(-231.7 \sim-29.0)$ & 0.012 & 1,435 & $29.4(-68.7 \sim 127.4)$ & 1.000 \\
\hline$>10$ years* & 1,494 & $86.6(31.6 \sim 141.6)$ & 0.002 & 1,462 & $56.4(4.4 \sim 108.7)$ & 0.029 \\
\hline
\end{tabular}

\#Age, HR, DBP, serum glucose, BMI, TGs, and gender were adjusted for analysis.

*The 39 persons who denied being smokers were excluded.

baPWV, brachial-ankle pulse wave velocity; CI, confidence interval. Other abbreviations see in Table 1.

Table 3. Comparison of baPWV $(\mathrm{cm} / \mathrm{s})$ Between Male and Female in Different Age Groups

\begin{tabular}{|c|c|c|c|c|c|c|}
\hline \multirow[b]{2}{*}{ Smoking status } & \multicolumn{3}{|c|}{$<50$ years } & \multicolumn{3}{|c|}{$>50$ years } \\
\hline & $\begin{array}{c}\text { Male } \\
(n=254)\end{array}$ & $\begin{array}{l}\text { Female } \\
(\mathrm{n}=225)\end{array}$ & P value ${ }^{\#}$ & $\begin{array}{c}\text { Male } \\
(\mathrm{n}=210)\end{array}$ & $\begin{array}{l}\text { Female } \\
(\mathrm{n}=217)\end{array}$ & P value $\#$ \\
\hline Nons-mokers & $\begin{array}{c}1,300 \\
(1,268-1,332)\end{array}$ & $\begin{array}{c}1,232 \\
(1,208-1,257)\end{array}$ & 0.001 & $\begin{array}{c}1,525 \\
(1,478-1,572)\end{array}$ & $\begin{array}{c}1,583 \\
(1,547-1,620)\end{array}$ & 0.054 \\
\hline Passive smokers & $\begin{array}{c}1,277 \\
(1,230-1,323)\end{array}$ & $\begin{array}{c}1,225 \\
(1,156-1,293)\end{array}$ & 0.150 & $\begin{array}{c}1,457 \\
(1,344-1,571)\end{array}$ & $\begin{array}{c}1,549 \\
(1,398-1,699)\end{array}$ & 0.378 \\
\hline Active smokers & $\begin{array}{c}1,330 \\
(1,304-1,357)\end{array}$ & $\begin{array}{c}1,294 \\
(1,213-1,376)\end{array}$ & 0.408 & $\begin{array}{c}1,573 \\
(1,517-1,629)\end{array}$ & $\begin{array}{c}1,562 \\
(1,419-1,705)\end{array}$ & 0.887 \\
\hline
\end{tabular}

baPWV are mean $(95 \% \mathrm{CI})$

\#Age, HR, DBP, serum glucose, BMI, TGs, and gender were adjusted for analysis.

Abbreviations see in Tables 1,2.

smokers were $2.91 \mathrm{ng} / \mathrm{ml}$ and $147.62 \mathrm{ng} / \mathrm{ml}$, respectively. Among the active smoking people, 179 subjects were male, while 385 females were identified to be non-smokers. The distribution of sexes among various smoking groups is significantly different $\left(\chi^{2}=156.03, \mathrm{P}<0.001\right)$. Of 639 people who reported no cigarette smoking, according to the cotinine level, $542(85 \%)$ were affirmed as non-smokers, $58(9 \%)$ had evidence of being marked passive smokers, and $39(6 \%)$ were reclassified as active smokers. The characteristics of the participants are listed in Table 1. Passive smokers were 4.5 years younger on average than non-smokers. Active smokers vs non-smokers showed significantly higher BMI. Compared with passive smokers, active smokers had a higher SBP (132 vs $124 \mathrm{mmHg}, \mathrm{P}<0.001)$ and DBP (82 vs $78 \mathrm{mmHg}, \mathrm{P}=0.002$ ). Higher levels of TC were found in non-smokers vs passive smokers. Active smokers vs passive smokers had higher TG and glucose levels. Active smokers obviously had a higher morbidity of hypertension than the other subjects.

\section{Correlation of Cotinine and baPWV}

In the overall study population, the partial correlation coefficient was 0.097 between baPWV and the serum cotinine level ( $\mathrm{P}=0.013)$, controlling for age, HR, $\mathrm{DBP}$, serum glucose, BMI, TG, and gender. A significant partial correlation coefficient of 0.09 was found in Julu residents $(\mathrm{P}=$ $0.024)$.

\section{Comparision of baPWV Among Different Smoking Statuses and Different Smoking Durations}

As is shown in Table 2, active smokers vs non-smokers showed significantly higher baPWV $(1,450$ vs $1,396 \mathrm{~cm} / \mathrm{s}$, $\mathrm{P}=0.023)$ after adjusting for covariates, and participants who smoked longer than 10 years had a higher baPWV than non-smokers $(1,462$ vs $1,405 \mathrm{~cm} / \mathrm{s}, \mathrm{P}=0.029)$, although no significant differences existed between those smokers who had a smoking history less than 10 years and non-smokers. No significant differences existed between passive smokers and non-smokers in this study, even after adjusting for covariates.

Comparison of baPWV Between Males and Females Subjects were divided into 2 groups according to age (Table 3). For young non-smokers ( $<50$ years), men tended to have a higher baPWV than women $(\mathrm{P}=0.001)$, while no significant differences existed between the 2 sexes for active smokers in this age group $(\mathrm{P}=0.408)$. Male vs female had no significant differences between various smoking states in older groups.

\section{Discrepancy of baPWV Between Julu and Beijing Participants in Various Smoking States}

For non-smokers, citizens in Beijing had a higher mean value of baPWV than dwellers in Julu, even after adjusting for covariates $(1,495$ vs $1,370 \mathrm{~cm} / \mathrm{s}, \mathrm{P}<0.001)$. The discrepancy was less in passive and active smokers between Beijing and Julu participants $(\mathrm{P}=0.190$ and $\mathrm{P}=0.147)$.

\section{Comparison of baPWV Among Different Smoking Statuses in Poor Areas}

The smoking rate was higher in Julu than in Beijing participants $(24.7 \%$ vs $12.3 \%, \mathrm{P}<0.001)$. Thirteen percent of non-smokers from Julu were exposed to heavy passive smoke, much higher than the rate $(5.26 \%)$ in Beijing $(\mathrm{P}<$ 0.001). Further analysis, as demonstrated in Figure, shows that active smokers vs non-smokers in Julu had a higher baPWV after adjusting for covariates $(\mathrm{P}=0.017)$. No significant differences existed among various smoking groups in 


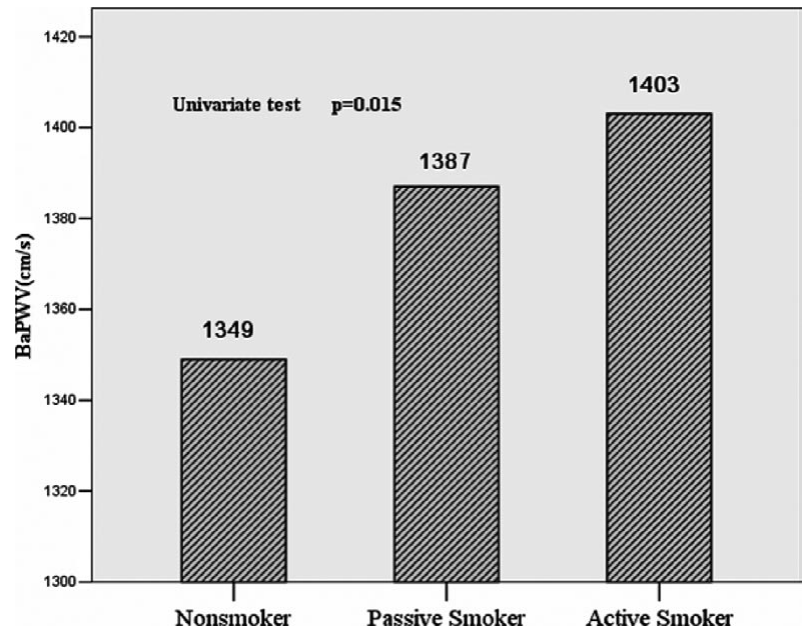

Figure. Comparison of the brachial-ankle pulse wave velocity (baPWV) among different smoking statuses of participants from a less developed area in North China. Active smokers had significantly a higher baPWV than non-smokers after adjusting for age, heart rate, diastolic blood pressure, serum glucose, body mass index, triglyceride, and gender $(\mathrm{P}=0.017)$.

Beijing $(\mathrm{P}>0.05)$ after adjusting for covariates.

\section{Discussion}

Smoking is the leading modifiable risk factor for cardiovascular disease ${ }^{23,24}$ Many mechanisms are responsible for arterial stiffness caused by cigarette exposure: smoking causes injury to the vascular endothelium, produces superoxide anions, reduces production and bioavailability of nitric oxide, increases production and release of endothelin, causes endothelial dysfunction, and generates pro-inflammatory alterations ${ }^{25-29}$ In accordance with other research, $3,4,14$ we verified in the present study that active smoke can aggravate arterial stiffness. However, compared with previous results using the questionnaire method, we deduced that smoking status judged by a biochemical indicator can be relatively more objective! ${ }^{8-21}$

Nicotine is responsible for tobacco addiction and is the most specific component of cigarette smoke. It is absorbed and is measurable in both active and passive smokers. However, nicotine levels in the blood fluctuate and the halflife of nicotine is approximately $2 \mathrm{~h}$ and hence it is poorly suited as a marker for monitoring chronic exposure. Cotinine is the major metabolite of nicotine, and is the analyte of choice as it fulfils the prerequisites of specificity and retention time ${ }^{30-32}$

According to the serum cotinine level, we found that several active smokers $(6 \%)$ had a trend of denying smoking during questioning, and some self-reported non-smokers were identified to be heavily exposed to environmental smoke, so the use of cotinine was very helpful in our epidemical study.

In the present study, cotinine verified that active smokers had significantly higher baPWV values after adjusting for covariates. Furthermore, to determine the relationship between arterial function and smoking duration, we extracted current smokers for further analysis, and those participants where cotinine verified them as being active smokers who initial denied being smokers were excluded from analysis because they lacked to report their smoking habit details.
Participants who smoked for longer than 10 years were found to have worse arterial stiffness, denoting that arterial aging and stiffening might be aggravated by a long history of smoking. In fact, the beginning age of cigarette smoking is very crucial to arterial heath $3^{3}$ Controlling the smoking rate in younger generations is an imperative task for developing countries. Recommendation of smoke cessation also should be given to new smokers, whose arterial problems are reversible before structural changes have been established 34

On the basis of the present study, arterial elasticity is better for women than men when they are younger than 50 years. This is in accordance with previous research, ${ }^{35-37}$ which suggests that estrogen might have beneficial effects on arterial stiffness ${ }^{38}$ However, in the present study, the baPWV of young female smokers tended to be the same as their male counterparts, which implies smoking will minimize the advantage a woman has before menopause. Therefore, we can deduce that smoking can influence the arterial function of young females more seriously than it does for males.

With respect to the comparison between passive smokers and non-smokers, no significant difference in baPWV was found after adjusting for covariates. This is associated with the better health conditions for passive smokers in the present study. For example, passive smokers in the present study have much lower rates of hypertension (27.7\%) and diabetes $(7.2 \%)$ than non-smokers, for whom the rates of hypertension and diabetes are $37.8 \%$ and $10.4 \%$, respectively. Meanwhile, although our cut-off value for passive/ active smokers $(15 \mathrm{ng} / \mathrm{ml})$ has been accepted by many studies ${ }^{15,20,22}$ there is still no real consensus on a precise target value, with ranges from lower than $10 \mathrm{ng} / \mathrm{ml}$ to higher than $25 \mathrm{ng} / \mathrm{ml} l^{18,39-42}$ Considering that the median value of cotinine levels for active smokers $(147.62 \mathrm{ng} / \mathrm{ml})$ was very high, it is reasonable to presume that some heavy secondhand cigarette smokers in the present study were misclassified as active smokers, which would contribute to concealing the impact of passive smoke to some extent. Accordingly, we cannot conclude that passive smoking has no bad effect on vascular function or doubt the usage of cotinine to diagnose passive smoking. On the contrary, using cotinine to discover more second-hand smokers is very useful in carrying out research for large populations, which could also investigate and confirm the influential effect of passive smoking on arterial health for the general public.

Cigarette smoking is particularly prevalent in mainland China, especially in Chinese males. ${ }^{43}$ As one of the poorest towns supported by national funds, Julu had been thought to have a lower smoking rate than other developed areas in China. However, according to the present study, the tobacco exposure rate in this poor town was surprisingly higher than that in Beijing. Further analysis demonstrated that nonsmokers in Beijing had a higher mean value of baPWV than dwellers in Julu, but the discrepancies were lessened in passive and active smokers between the 2 areas. Furthermore, although active smoking contributed to significant arterial stiffness in Julu participants, a similar phenomenon could not be found in modernized Beijing, even though the exposure degree was almost the same between Beijing and Julu participants in passive smokers and active smokers (median cotinine level 2.76 vs $2.92 \mathrm{ng} / \mathrm{ml}, \mathrm{P}=0.795$ and 148 vs $144 \mathrm{ng} / \mathrm{ml}, \mathrm{P}=0.889$ ). Therefore, we believe that chronic smoke exposure brings more harm to the arterial heath for farmers living in poor areas than it does for citizens from 
developed cities in North China. A genetic difference is unlikely in the present study, as Beijing is completely geographically surrounded by the Hebei province and the majority of subjects studied in Beijing originated from Hebei. Compared with serial studies conducted with South Chinese participants by Kam et al, 29 which indicated that both active and passive smoking had less harmful effects on endothelium-dependent and endothelium-independent arterial dilation for rural people, we seem to have found different results, and this is very likely to be related to the huge contrast between the 2 areas studied. In the present study, Beijing, the host city of the 2008 Olympic Games, experienced a booming economy during these years. Meanwhile, as one of the most prosperous cities in Mainland China, with almost all of the best domestic universities clustered there, Beijing people have a high cultural quality. The condition is totally opposite for the region of Julu. As one of the poorest areas in China, the participants coming for this medical examination are farmers living nearby, whose incomes are the lowest in the country. Consequently, knowledge and treatment rates of chronic disease are very low, and imported medicine useful to relieve arterial stiffness and atherosclerosis including angiotensin-converting enzyme inhibitors, angiotensin receptor blockers, calcium channel blockers, and statins are not commercially available there. All of these factors make the apparently younger countryside dwellers more vulnerable to the harmful effects of cigarette exposure, presenting as the relatively higher baPWV value for smokeexposed people in the rural area.

\section{Study Limitations}

One shortcoming of using cotinine to determine smoking states is that it can not reflect the accurate condition for a very long period of time, because of its limited existence in the blood, with a half-life of $20 \mathrm{~h}$; ${ }^{44}$ however, it does have a longer existence than nicotine. So in terms of very longterm smoking conditions, we have to believe that people's smoking state remains stable over a long period, which might influence the accuracy of our results.

\section{Conclusions}

Active smokers, as confirmed by the use cotinine, have worse arterial stiffness, and long-term smoking (>10 years) can cause marked arterial stiffness. Active smoking might influence the arterial function of young females more seriously than their male counterparts. We should pay close attention to the underestimated smoking rate in less developed areas, as cigarette smoke exposure might bring about more serious effects on arterial stiffness in participants from poor areas than those from modernized cities in North China.

\section{Acknowledgments}

This study is supported by the National Natural Science Foundation of People's Republic of China (30671795). The authors also especially want to thank the professional staff in Julu Hospital who assisted us in participant recruitment.

\section{References}

1. He J, Gu D, Wu X, Reynolds K, Duan X, Yao C, et al. Major causes of death among men and women in China. $N$ Engl J Med 2005; 353: $1124-1134$

2. Celermajer DS, Sorensen KE, Georgakopoulos D, Bull C, Thomas O, Robinson J, et al. Cigarette smoking is associated with dose-related and potentially reversible impairment of endothelium-dependent dila- tion in healthy young adults. Circulation 1993; 88: 2149-2155.

3. Li H, Srinivasan SR, Berenson GS. Comparison of the measures of pulsatile arterial function between asymptomatic younger adult smokers and former smokers: The Bogalusa Heart Study. Am J Hypertens 2006; 19: 897-901.

4. Mahmud A, Feely J. Effect of smoking on arterial stiffness and pulse pressure amplification. Hypertension 2003; 41: 183-187.

5. Thomas GN, Chook P, Yip TW, Kwong SK, Chan TY, Qiao M, et al. Smoking without exception adversely affects vascular structure and function in apparently healthy Chinese: Implications in global atherosclerosis prevention. Int J Cardiol 2008; 128: 172-177.

6. Mack WJ, Islam T, Lee Z, Selzer RH, Hodis HN. Environmental tobacco smoke and carotid arterial stiffness. Prev Med 2003; 37: $148-154$.

7. Mahmud A, Feely J. Effects of passive smoking on blood pressurre waveform in healthy young adults-influence of gender. $\mathrm{Br} \mathrm{J} \mathrm{Clin}$ Pharmacol 2004; 57: 37-43.

8. Park SM, Seo HS, Lim HE, Shin SH, Park CG, Oh DJ, et al. Assessment of arterial stiffness index as a clinical parameter for atherosclerotic coronary artery disease. Circ J 2005; 69: 1218-1222.

9. Kubozono T, Miyata M, Ueyama K, Nagaki A, Otsuji Y, Kusano K, et al. Clinical significance and reproducibility of new arterial distensibility index. Circ J 2007; 71: 89-94.

10. Hongo M, Tsutsui H, Mawatari E, Hidaka H, Kumazaki S, Yazaki Y, et al. Fluvastatin improves arterial stiffness in patients with coronary artery disease and hyperlipidemia: A 5-year follow-up study. Circ J 2008; 72: $722-728$.

11. Yamashina A, Tomiyama H, Takeda K, Tsuda H, Arai T, Hirose K, et al. Validity, reproducibility, and clinical significance of noninvasive brachial-ankle pulse wave velocity measurement. Hypertens Res 2002; 25: 359-364.

12. Im JA, Lee JW, Shim JY, Lee HR, Lee DC. Association between brachial-ankle pulse wave velocity and cardiovascular risk factors in healthy adolescents. J Pediatr 2007; 150: 247-251.

13. Jee SH, Park J, Jo I, Lee J, Yun S, Yun JE, et al. Smoking and atherosclerotic cardiovascular disease in women with lower levels of serum cholesterol. Atherosclerosis 2007; 190: 306-312.

14. Jatoi NA, Jerrard-Dunne P, Feely J, Mahmud A. Impact of smoking and smoking cessation on arterial stiffness and aortic wave reflection in hypertension. Hypertension 2007; 49: 981-985.

15. Heller WD, Scherer G, Sennewald E, Adlkofer F. Misclassification of smoking in a follow-up population study in southern Germany. J Clin Epidemiol 1998; 51: 211-218.

16. Malcon MC, Menezes AM, Assunção MC, Neutzling MB, Hallal PC. Agreement between self-reported smoking and cotinine concentration in adolescents: A validation study in Brazil. J Adolesc Health 2008; 43: $226-230$.

17. Pérez-Stable EJ, Benowitz NL, Marín G. Is serum cotinine a better measure of cigarette smoking than self-report? Prev Med 1995; 24: $171-179$.

18. Martínez ME, Reid M, Jiang R, Einspahr J, Alberts DS. Accuracy of self-reported smoking status among participants in a chemoprevention trial. Prev Med 2004; 38: 492-497.

19. England LJ, Grauman A, Qian C, Wilkins DG, Schisterman EF, Yu $\mathrm{KF}$, et al. Misclassification of maternal smoking status and its effects on an epidemiologic study of pregnancy outcomes. Nicotine Tob Res 2007; 9: 1005-1013.

20. Venn A, Britton J. Exposure to secondhand smoke and biomarkers of cardiovascular disease risk in never-smoking adults. Circulation 2007; 115: $990-995$.

21. Benowitz NL. Cotinine as a biomarker of environmental tobacco smoke exposure. Epidemiol Rev 1996; 18: 188-204.

22. Whincup PH, Gilg JA, Emberson JR, Jarvis MJ, Feyerabend C, Bryant A, et al. Passive smoking and risk of coronary heart disease and stroke: Prospective study with cotinine measurement. BMJ 2004; 329: 200-205.

23. Ezzati M, Henley SJ, Thun MJ, Lopez AD. Role of smoking in global and regional cardiovascular mortality. Circulation 2005; 112: 489497.

24. Teo KK, Ounpuu S, Hawken S, Pandey MR, Valentin V, Hunt D, et al. Tobacco use and risk of myocardial infarction in 52 countries in the INTERHEART study: A case-control study. Lancet 2006; 368: 647-658.

25. Rahman MM, Laher I. Structural and functional alteration of blood vessels caused by cigarette smoking: An overview of molecular mechanisms. Curr Vasc Pharmacol 2007; 5: 276-292.

26. Yufu K, Takahashi N, Okada N, Shinohara T, Hara M, Saikawa T, et al. Influence of systolic blood pressure and cigarette smoking on endothelial function in young healthy people. Circ J 2009; 73: 174178. 
27. Adamopoulos D, van de Borne P, Argacha JF. New insights into the sympathetic, endothelial and coronary effects of nicotine. Clin Exp Pharmacol Physiol 2008; 35: 458-463.

28. Celermajer DS, Adams MR, Clarkson P, Robinson J, McCredie R, Donald A, et al. Passive smoking and impaired endothelium-dependent arterial dilatation in healthy young adults. N Engl J Med 1996; 334: $150-154$.

29. Woo KS, Chook P, Leong HC, Huang XS, Celermajer DS. The impact of heavy passive smoking on arterial endothelial function in modernized Chinese. J Am Coll Cardiol 2000; 36; 1228-1232.

30. Willers S, Skarping G, Dalene M, Skerfving S. Urinary cotinine in children and adults during and after semiexperimental exposure to environmental tobacco smoke. Arch Environ Health 1995; 50: 130 138.

31. Domino EF. Nontobacco sources of cotinine in the urine of nonsmokers. Clin Pharmacol Ther 1995; 57: 479.

32. Bakoula CG, Kafritsa YJ, Kavadias GD, Lazopoulou DD, Theodoridou MC, Maravelias KP, et al. Objective passive-smoking indicators and respiratory morbidity in young children. Lancet 1995; 346: $280-281$.

33. Planas A, Clará A, Marrugat J, Pou JM, Gasol A, de Moner A, et al. Age at onset of smoking is an independent risk factor in peripheral artery disease development. J Vasc Surg 2002; 35: 506-509.

34. Rehill N, Beck CR, Yeo KR, Yeo WW. The effect of chronic tobacco smoking on arterial stiffness. Br J Clin Pharmacol 2006; 61: 767 773.

35. Koivistoinen T, Kööbi T, Jula A, Hutri-Kähönen N, Raitakari OT, Majahalme S, et al. Pulse wave velocity reference values in healthy adults aged 26-75 years. Clin Physiol Funct Imaging 2007; 27: $191-$ 196
36. Albaladejo P, Laurent P, Pannier B, Achimastos A, Safar M, Benetos A. Influence of sex on the relation between heart rate and aortic stiffness. J Hypertens 2003; 21: 555-562.

37. Mitchell GF, Parise H, Benjamin EJ, Larson MG, Keyes MJ, Vita JA, et al. Changes in arterial stiffness and wave reflection with advancing age in healthy men and women: The Framingham Heart Study. Hypertension 2004; 43: 1239-1245.

38. Rajkumar C, Kingwell BA, Cameron JD, Waddell T, Mehra R, Christophidis N, et al. Hormonal therapy increases arterial compliance in postmenopausal women. $J$ Am Coll Cardiol 1997; 30: 350356.

39. Chazeron I, Daval S, Ughetto S, Richard D, Nicolay A, Lemery D, et al. GC-MS determined cotinine in an epidemiological study on smoking status at delivery. Pulm Pharmacol Ther 2008; 21: 485488.

40. Bernert JT Jr, McGuffey JE, Morrison MA, Pirkle JL. Comparison of serum and salivary cotinine measurements by a sensitive high-performance liquid chromatography-tandem mass spectrometry method as an indicator of exposure to tobacco smoke among smokers and nonsmokers. J Anal Toxicol 2000; 24: 333-339.

41. Vartiainen E, Seppälä T, Lillsunde P, Puska P. Validation of self reported smoking by serum cotinine measurement in a communitybased study. J Epidemiol Community Health 2002; 56: 167-170.

42. Patrick DL, Cheadle A, Thompson DC, Diehr P, Koepsell T, Kinne S. The validity of self-reported smoking: A review and meta-analysis. Am J Public Health 1994; 84: 1086-1093.

43. Lam TH, He Y, Li LS, Li LS, He SF, Liang BQ. Mortality attributable to cigarette smoking in China. JAMA 1997; 278: 1505-1508.

44. Benowitz NL, Kuyt F, Jacob P III, Jones RT, Osman AL. Cotinine disposition and effects. Clin Pharmacol Ther 1983; 34: 604-611. 